\title{
Peer-Victimization and Mental Health Problems in Adolescents: Are Parental and School Support Protective?
}

\author{
Christina Stadler · Julia Feifel • Sonja Rohrmann • Robert Vermeiren • \\ Fritz Poustka
}

Published online: 10 March 2010

(C) The Author(s) 2010. This article is published with open access at Springerlink.com

\begin{abstract}
The aim of this study was to investigate the frequency and effects of peervictimization on mental health problems among adolescents. Parental and school support were assumed as protective factors that might interact with one another in acting as buffers for adolescents against the risk of peer-victimization. Besides these protective factors, age and gender were additionally considered as moderating factors. The Social and Health Assessment survey was conducted among 986 students aged 11-18 years in order to assess peer-victimization, risk and protective factors and mental health problems. For mental health problems, the Strengths and Difficulties Questionnaire (SDQ) was used. Effects of peer-victimization on mental health problems were additionally compared with normative SDQ data in order to obtain information about clinically relevant psychopathology in our study sample. Results of this study show that peer-victimization carries a serious risk for mental health problems in adolescents. School support is effective in both male and female adolescents by acting as a buffer against the effect of victimization, and school support gains increasing importance in more senior students. Parental support seems to be protective against maladjustment, especially in peer-victimized girls entering secondary school. Since the effect of peer-victimization can be reduced by parental and school support, educational interventions are of great importance in cases of peer-victimization.
\end{abstract}

Keywords Victimization · Protective factors · Parent support · School support · Mental health problems

C. Stadler $(\bowtie) \cdot$ J. Feifel $\cdot$ F. Poustka

Department of Child and Adolescent Psychiatry, Johann Wolfgang Goethe University,

Deutschordenstrasse 50, 60590 Frankfurt am Main, Germany

e-mail: Christina.Stadler@em.uni-frankfurt.de

S. Rohrmann

Department of Psychology, J.W. Goethe University, Frankfurt am Main, Germany

R. Vermeiren

Curium-LUMC, Leiden University Medical Center, Leiden, The Netherlands 


\section{Introduction}

Physical attacks, social manipulation and verbal victimization are the most frequent and disturbing acts of aggression in schools. Acts of both victimization and bullying [1-3] are found and have extensive parallels: each consists of negative actions that occur repeatedly and over a longer period of time, carried out by one or more individuals, with the intention of inflicting harm either by direct (verbal/physical attacks) or indirect action (exclusion from the group). In accordance with Olweus [4], the terms "victimization" and "bullying" do not apply when two persons of approximately the same strength are fighting or quarrelling with each other. Notably, peer-victimization is especially prevalent in the elementary school years, with a mean rate of victimization of $23 \%$ of students across five urban cities [5].

The stability of victimization is relatively high, and it was shown that victimization exerts negative effects on children's development [6]. Repeated peer-victimization leads to a chronic state of stress, endangering children's healthy development [7]. Peer-victimization was shown to contribute to internalizing symptoms, such as anxiety, depression, and low-self-esteem [8], as well as to externalizing problems, such as aggression, disruptiveness, and other provocative behavior symptoms [9-11].

Despite the well-documented association between peer-victimization and maladaptive development [12], not all peer-victimized children are at increased risk for developing mental health problems. Some children seem to be resilient against victimization despite exposure to a high-risk environment, a phenomenon called 'adaptive success' [13]. To explain adaptive success, protective factors like social support have to be considered [14]. Protective factors are processes that interact with risk factors in reducing the probability of negative outcomes [15-17]. Thus, the same factors that have protective effects under certain circumstances may not be protective under different conditions. Understanding the processes that protect adolescents from maladaptive development and identifying these factors might be useful for developing more effective intervention strategies for peervictimized children. According to the literature, parental as well as school support play protective roles in adolescent development:

\section{Parental Support}

The quality of parent-adolescent relations is a widely cited factor shown to protect children despite adverse environments $[18,19]$. Supportive parent-child relationships, as measured by parental warmth, supervision, support and involvement, were found to reduce externalizing behavior. Thus, positive family resources coincide with an absence of behavioral problems, whereas an adverse family climate is a main negative contributor to mental health problems in general [20].

\section{School Support}

Attachment to school was shown to relate to better physical health, to lower levels of smoking and drinking, and to higher participation in extracurricular activities [21, 22]. Hill and Madhere [23] found teacher support to increase socially competent behavior in the classroom. Furthermore, it can be supposed that school support can compensate for a lack of parental support, possibly also protecting against the impacts of risk factors like peervictimization. 
Gender and age are further factors moderating the relationship between risk factors and the development of adolescents. According to Luthar and colleagues [24, 25], the construct of resilience is not unidimensional or stable across multiple contexts, but refers to adaptation to and engagement within specific environmental contexts. A longitudinal study by Hanish and Guerra [10] revealed that gender and age differences must be considered when predicting the severity of peer-victimization consequences like externalizing, internalizing and social problems. More recently, Seiffge-Krenke [26] showed that gender differences exist in the quality and frequency of peer-victimization. Furthermore, gender-linked vulnerabilities in the association of victimization and maladjustment have been found [27-29]. Gorman-Smith et al. [30] showed that male adolescents were protected against violence exposure in positively interacting families. For these reasons, whether protective factors exert different effects within the context of victimization in female versus male adolescents should be investigated.

Thus, the aim of this study was to investigate (1) the frequency of peer-victimization in female and male adolescents and its association with mental health problems. Specifically, the objective was to investigate whether (2) peer-victimized adolescents are protected from developing mental health problems by parental and school support. We expected peervictimization to be associated with poor mental health, while parental and school support were considered to act as buffers against developing problems. In addition, we assessed whether adolescents, across the demographic contexts of gender and age, benefit similarly from the protective factors in question. The impact of age was considered, as it may be assumed that the studied protective factors act differently in middle school versus senior high school students (3). Finally, effects of peer-victimization on mental health problems were compared with normative data in order to obtain additional information about clinically relevant psychopathology.

\section{Method}

Participants and Procedure

The sample consisted of 986 subjects, 513 females (mean age $=14.68$ years, SD $=1.64$ ) and 473 males (mean age $=14.69$ years, $\mathrm{SD}=1.65$ ).

The study was conducted in seven public secondary schools in Frankfurt, Germany. Schools were chosen to represent all different school types in Germany (Hautpschule, Realschule, Gymnasium, Gesamtschule). The grade levels included ranged from 7 to 11, encompassing children from 11 to 18 years of age. In this study, adolescents aged 11-14 years were defined as middle school students and adolescents aged 15-18 years as senior students. The survey was approved by the administrative school boards as well as by the administrations of the participating schools. Students' parents were informed about the study and had to return a consent form for their child to participate. In total, the rate of participation was $80 \%$ due to a lack of parental consent or absence on the day of testing for the remaining $20 \%$ of students. Before starting the assessment, students signed assent forms in which confidentiality was ensured. Students completed the survey in class on a regular school day. Trained administrators assisted the students during completion of the survey. 
Instruments

Data were collected using the Social and Health Assessment (SAHA), a survey originally developed by Weissberg et al. [31] and modified by Schwab-Stone et al. [32, 33]. The SAHA has been approved by the Yale University Institutional Review Board. The survey assesses adolescents' attitudes towards school, family and high-risk behavior as well as emotional and behavioral problems. The German translation followed established guidelines and was developed by two bilingual interpreters. Back translations, which were compared with the originals, were made by an independent interpreter. Likert-type scale totals were obtained by averaging individual item scores.

SAHA scales used in this study: For mental health problems, the Strengths and Difficulties Questionnaire (SDQ) was used, a 25-item behavioral screening questionnaire for 4- to 16-year-olds [34]. In several representative samples, it was shown that the SDQ is as suitable as the Child Behavior Checklist [35] for identifying mental health problems in children [36, 37]. Respondents were asked to rate the occurrence of various psychopathology symptoms within the last six months. Five subscales of five items each assess protective and problem behavior: prosocial behavior, hyperactivity and attention problems, emotional problems, conduct problems and problems with peers. Items assessing behavioral problems are added up to generate a total score (20 items). Since our study as well as prior studies [37] showed that psychometric properties of the total SDQ scale are more satisfactory than SDQ subscales (Cronbach's alpha $=.48-.68$ ), the total scale was used to investigate the effects of peer-victimization on general mental health problems. Cronbach's alpha for the total SDQ scale in our German sample is .75. For middle school students, we were able to compare the effect of peer-victimization on mental health problems with normative data. These normative data and clinically relevant cut-offs for the SDQ self-report form were obtained by Meltzer et al. [38] from a representative sample of 11- to 15-year-old adolescents. In our study sample, significant mental health problems were judged to be present if adolescents' total SDQ score was more than 1.5 standard deviations above the mean score of typically developing children.

\section{Peer-Victimization}

Nine items assessing peer-victimization were adapted from the multidimensional peervictimization scale developed by Mynard and Joseph [39] comprising physical victimization (e.g., "Other kids ... hurt me physically in some way"), social manipulation (e.g., "...tried to get me into trouble with my friends"), verbal victimization (e.g., "...called me names or swore at me”) and attacks on property (e.g., “...tried to break or damage something of mine"). Items are scored on 4-point scales describing the frequency of victimization $(1=$ "not at all", $2=$ "once", $3=$ "two to three times", $4=$ "four or more times"). Cronbach's alpha in the German study is .83. Respondents were requested to rate peer-victimization within the last year.

A cut-off score was set at one standard deviation above the sample mean; thus, peervictimized students had been victimized more than 2-3 times in the last year, whereas students with low victimization scores had never been victimized or had been victimized only once in the last year. 


\section{Parental Support}

Parental support comprises the composite of four parental support scales assessing parental warmth (five items, e.g., "My parents are kind to me"; Cronbach's alpha $=.83$ ), parental involvement (six items, e.g., "My parents ask me about my life"; Cronbach's alpha = .77), parental supervision (eight items, e.g., "My parents tell me what time I have to be at home"; Cronbach's alpha = .79), and parental inconsistency (five items, e.g., "My parents nag me about little things"; Cronbach's alpha $=.73$ ). Parental inconsistency (items have been converted) was included since Trumpeter et al. [40] showed that parental inconsistency correlates with psychological maladjustment. Items were scored on 4-point scales ranging from $0=$ never to $3=$ often.

\section{School Support}

School support comprises the composite of three school support scales: Negative school climate (seven items, e.g., "Teachers often shout at students", Cronbach's alpha $=.77$ ), perceived teacher support (eight items, e.g., "Teachers don't often take time to give individual attention"; Cronbach's alpha =.63) and attachment to school (five items, e.g., "I like school", Cronbach's alpha $=.78$ ).

A proxy, psychosocial risk factor, was calculated and integrated into the statistical analyses. The proxy consisted of a composite index including single-parent family status (divorced, separated or widowed) and parental unemployment. In our sample, no risk was found in 68.3 percent of students; in 27.2 percent, one risk factor was found; and in 4.4 percent, two psychosocial risk factors were found.

\section{Statistical Analyses}

Chi-square and independent sample t-tests were first calculated for univariate comparisons of demographic characteristics. Students were divided into two groups: 11- to 14-year-old adolescents, defined as middle school students, and 15- to 18-year-old adolescents, defined as senior high school students. Furthermore, the frequency of peer-victimization in female and male adolescents was calculated, and whether peer-victimization differs between middle school students and senior high school students was investigated (independent sample $t$-test). Pearson correlation coefficients between the study variables (peer-victimization, parental and school support, psychosocial risk) were calculated separately for males and females. In order to investigate how the resilience factors of parental and school support protect adolescents exposed to peer-victimization against developing mental health problems, two separate hierarchical regression analyses were performed with $z$-standardized variables. First, the influences of peer-victimization and protective factors on mental health problems were investigated, and in addition, gender effects were considered. The dependent variable, level of mental health problems, was regressed on four blocks of independent variables. In the first block, peer-victimization, parental support, school support and psychosocial risk were included. The first block also consisted of a dummy coded variable for gender $(0=$ females, $1=$ males $)$. In the second block, six-two-way interactions were entered according to the guidelines of Aiken and West (1991) [41]. The moderating interactions of victimization $\times$ parent support, victimization $\times$ school support, and parent support $\times$ school support were entered, as well as exploratory gender interactions. In the third block, the three-way parent support $\times$ school support $\times$ gender 
interactions were included to test the joint moderating effect on mental health problems. Finally, the fourth step of the interaction included the four-way victimization $\times$ parent support $\times$ school support $\times$ gender interaction.

The procedure of our second hierarchical analysis was identical, but instead of gender, age was integrated as a dummy variable $(0=$ middle school students, $1=$ senior high school students) in order to investigate the influences of peer-victimization and protective factors in the context of different age groups. Since normative data for self-rated mental health problems [38] exist only for 11- to 15-year-old adolescents, the clinical impact of victimization on mental health problems will be discussed for middle school students only.

\section{Results}

Description of the Sample

Demographic characteristics of the final sample are presented in Table 1. Students did not differ significantly concerning school form. The majority of students (70\%) had married or remarried parents, and the rate of unemployment in this study sample was $14.9 \%$ in fathers. The ethnic composition of the final sample was predominately non-German (Germany: 44.4\%, Turkey: 16.8\%, Eastern Europe: $11.0 \%$, Africa: 5.2\%, Asia: 9.7\%, America: $0.3 \%$, other European countries: 9.2\%, unknown: 3.4\%). As these figures show, 55.6\% of students reported an immigrant background, an accurate reflection of the local public school population.

Table 1 Demographic characteristics of the study sample

\begin{tabular}{|c|c|c|c|c|}
\hline Variable & $\begin{array}{l}\text { Total sample } \\
(N=986)\end{array}$ & $\begin{array}{l}\text { Girls } \\
(N=513)\end{array}$ & $\begin{array}{l}\text { Boys } \\
(N=473)\end{array}$ & Statistic \\
\hline Age mean & $\begin{array}{l}M=14.68 \\
\quad(\mathrm{SD}=1.64)\end{array}$ & $\begin{array}{l}M=14.67 \\
\quad(\mathrm{SD}=1.64)\end{array}$ & $\begin{array}{l}M=14.69 \\
\quad(\mathrm{SD}=1.65)\end{array}$ & $t=.22, p=.83$ \\
\hline \multicolumn{5}{|l|}{ School form } \\
\hline Comprehensive school & $46.3 \%$ & $24.0 \%$ & $22.3 \%$ & $\begin{array}{c}\chi=.31, d f=3 \\
p=.38\end{array}$ \\
\hline Secondary grammar school & $15.3 \%$ & $7.2 \%$ & $8.1 \%$ & \\
\hline Intermediate secondary school & $21.9 \%$ & $11.6 \%$ & $10.3 \%$ & \\
\hline Grammar school & $16.5 \%$ & $9.4 \%$ & $7.1 \%$ & \\
\hline Migration background & $55.6 \%$ & $52.6 \%$ & $47.4 \%$ & $\begin{array}{c}\chi=.004, d f=1 \\
p=.95\end{array}$ \\
\hline \multicolumn{5}{|l|}{ Parents } \\
\hline Married or remarried & $70.0 \%$ & $37.6 \%$ & $32.4 \%$ & $\begin{array}{c}\chi=2.82, d f=3 \\
p=.42\end{array}$ \\
\hline Divorced or separated & $20.7 \%$ & $9.7 \%$ & $11.0 \%$ & \\
\hline Widowed & $2.5 \%$ & $1.3 \%$ & $1.2 \%$ & \\
\hline Never married & $6.8 \%$ & $3.5 \%$ & $3.3 \%$ & \\
\hline Fathers's unemployment & $14.9 \%$ & $7.8 \%$ & $7.1 \%$ & $\begin{array}{c}\chi=1.96, d f=2 \\
p=.38\end{array}$ \\
\hline
\end{tabular}


Frequency of Peer-Victimization and Its Association with Mental Health Problems

As gender might be an important factor moderating the relationship between peer-victimization and mental health problems, separate analyses were conducted for male and female adolescents. Using our definition of peer-victimization, $19.8 \%$ of all students were frequently victimized ( $12 \%$ of male students, $7.8 \%$ of female students). There was a decline in peer-victimization of $4.4 \%$ from middle school students to senior high school students. Whereas in boys the decline was quite low, from $12.5 \%$ in middle school students to $11.5 \%$ in senior high school students, in female students, peer-victimization in middle school students was $9.6 \%$ and in senior high school students $6.5 \%$. In female students only, we found a statistical trend for this decline $(t=-1.70, p<.1)$.

Correlations between the study variables for males and females are presented in Table 2. For girls as well as boys, a significant association between peer-victimization and mental health problems was found. Only in female students, peer-victimization was negatively correlated with both school and parental support. In addition a positive correlation between victimization and psychosocial risk was found. In male students, no significant correlation between parental support and peer-victimization was found. Although accounting only for minor variance, the correlation between school support and victimization reached significance $(r=-.19)$. Furthermore, psychosocial risk in boys was significantly associated with mental health problems $(r=.15)$.

\section{Influence of Parental Support and School Support as Buffers Against} Peer-Victimization

The first hierarchical regression analysis investigated the moderating effects of parental and school support on the relationship between peer-victimization and mental health, while considering gender. Block 1, investigating main effects (peer victimization, gender, parental and school support and psychosocial risk) accounted for $28 \%$ of the variance in mental health problems. Gender significantly contributed to mental health problems, with females scoring higher. Peer-victimized students were affected significantly more often $(\beta=.36, p<.01)$. In addition, the first block revealed school support $(\beta=-.27, p<.01)$ and parental support $(\beta=-.08, p<.05)$ to be negatively associated with mental health problems.

The second block of the regression, including two-way interactions, accounted for $1 \%$ of the total variance. The victimization $\times$ parent support interaction reached significance $(\beta=-.07, p<.05)$ as well as the interaction between victimization and gender $(\beta=$ $-.10, p<.05)$.

Table 2 Correlations among the measured variables for girls (italic and bold) and boys (below diagonal)

\begin{tabular}{lllllr}
\hline & 1 & 2 & 3 & 4 & 5 \\
\hline 1. Peer-victimization & - & $-.28^{* *}$ & $-.18^{* * *}$ & $.15^{* * *}$ & $.47^{* *}$ \\
2. School support & $-.19^{* *}$ & - & $.32^{* *}$ & -.01 & $-.35^{* *}$ \\
3. Parent support & -.08 & $.30^{* *}$ & - & -.01 & $-.40^{* *}$ \\
4. Psychosocial risk & $.15^{* *}$ & $-.10^{*}$ & -.11 & - & .08 \\
5. Total SDQ & $.41^{* *}$ & $-.32^{* *}$ & $-.30^{* *}$ & $.14 * *$ & - \\
\hline
\end{tabular}

$* p<.05 ; * * p<.01$ 
The third block of variables, accounting for an additional $1 \%$ of the variance in mental health problems, is the crucial test of whether male and female peer-victimized students benefit differently from parental and/or school support. The three-way interaction of victimization $\times$ parent support $\times$ gender reached significance $(\beta=.11, p<.05)$, whereas the victimization $\times$ school support $\times$ gender interaction was not statistically significant (Table 3).

To examine whether peer-victimized students differ not only in relation to gender, but also in relation to age with regard to protective factors, a second regression analysis was conducted.

Block 1, consisting of main effects, accounted for $25 \%$ of the variance in mental health problems. In agreement with our first analysis, peer-victimization was positively associated $(\beta=.32, p<.01)$ and school support was negatively associated $(\beta=-.30, p<.01)$ with mental health problems. Parental support, however, as well as psychosocial risk, did not reach statistical significance. In addition, age significantly contributed to mental health problems $(\beta=.08, p<.05)$, indicating that older students were slightly more affected.

The second block of the regression, including the two-way interactions, did not account for additional variance. None of the two-way interactions were statistically significant.

The third block of variables - the crucial test for investigating the moderating effect with regard to age-accounted for $1 \%$ of the variance in mental health problems. The three-way interaction of victimization $\times$ school support $\times$ age reached significance $(\beta=.-14, p<.01)$, and the victimization $\times$ parent support $\times$ age interaction was also statistically significant $(\beta=-.10, p<.05)$ (Table 4$)$.

To illustrate further the significant victimization $\times$ school support $\times$ age interaction, mean SDQ scores are represented in relation to school support in victimized as well as

Table 3 Predictors on mental health problems in male and female adolescents

\begin{tabular}{|c|c|c|c|c|}
\hline & \multicolumn{4}{|c|}{ Mental health problems (SDQ total score) } \\
\hline & & B at entry & SE B & $\beta$ \\
\hline Psychosocial risk & Block 1 & .21 & .15 & .04 \\
\hline Victimization & & 1.95 & .16 & $.36 * *$ \\
\hline Parent support & & -.43 & .15 & $-.08 *$ \\
\hline School support & & -1.46 & .16 & $-.27 * *$ \\
\hline Gender & & -2.02 & .30 & $-.19 * *$ \\
\hline Victimization $\times$ parent support & Block 2 & -.39 & .16 & $-.07 *$ \\
\hline Victimization $\times$ school support & & .00 & .15 & .00 \\
\hline School support $\times$ parent support & & -.14 & .15 & -.03 \\
\hline Victimization $\times$ gender & & -.69 & .32 & $-.10^{*}$ \\
\hline Parent support $\times$ gender & & .47 & -.30 & .07 \\
\hline School support $\times$ gender & & -.29 & .32 & -.04 \\
\hline Victimization $\times$ parent support $\times$ gender & Block 3 & .78 & .35 & $.11 *$ \\
\hline Victimization $\times$ school support $\times$ gender & & -.48 & .32 & -.07 \\
\hline Parent support $\times$ school support $\times$ gender & & -.08 & .31 & .01 \\
\hline Victimization $\times$ parent support $\times$ school support & & -.03 & .15 & -.01 \\
\hline
\end{tabular}

$\mathrm{R} 2=.28$ for step $1(p<.01) ; \Delta \mathrm{R} 2=.005$ for step $2(p=.058) ; \Delta \mathrm{R} 2=.01$ for step $3(p=.18)$, $* p<.05, * * p<.01$ 
Table 4 Predictors on mental health problems in 11-14 and 15-18 year old Adolescents

\begin{tabular}{|c|c|c|c|c|}
\hline & \multicolumn{4}{|c|}{ Mental health problems (SDQ total score) } \\
\hline & & B at entry & SE B & $\beta$ \\
\hline Psychosocial risk & Block 1 & .16 & .16 & .03 \\
\hline Victimization & & 1.75 & .16 & $.32 * *$ \\
\hline Parent support & & -.24 & .16 & -.05 \\
\hline School support & & -1.62 & .16 & $-.30 * *$ \\
\hline Age & & .81 & .32 & $-.08 *$ \\
\hline Victimization $\times$ parent support & Block 2 & -.23 & .17 & -.04 \\
\hline Victimization $\times$ school support & & -.09 & .16 & .02 \\
\hline School support $\times$ parent support & & -.12 & .16 & -.02 \\
\hline Victimization $\times$ age & & -.09 & .26 & -.01 \\
\hline Parent support $\times$ age & & .50 & .34 & -.05 \\
\hline School support $\times$ age & & -.20 & .32 & -.02 \\
\hline Victimization $\times$ parent support $\times$ age & Block 3 & -.79 & .36 & $-.10 *$ \\
\hline Victimization $\times$ school support $\times$ age & & -.96 & .26 & $-.14 * *$ \\
\hline Parent support $\times$ school support $\times$ age & & -.03 & .43 & -.00 \\
\hline Victimization $\times$ parent support $\times$ school support & & -.05 & .16 & -.01 \\
\hline
\end{tabular}

$\mathrm{R} 2=.26$ for step $1(p<.01) ; \Delta \mathrm{R} 2=.01$ for step $2(p=.43) ; \Delta \mathrm{R} 2=.01$ for step $3(p=.01), * p<.05$, ** $p<.01$

Fig. 1 Level of mental health problems (SDQ total score) in victimized and nonvictimized middle-school students and senior students with high school support $(N=76)$ and low school support $(N=115)$

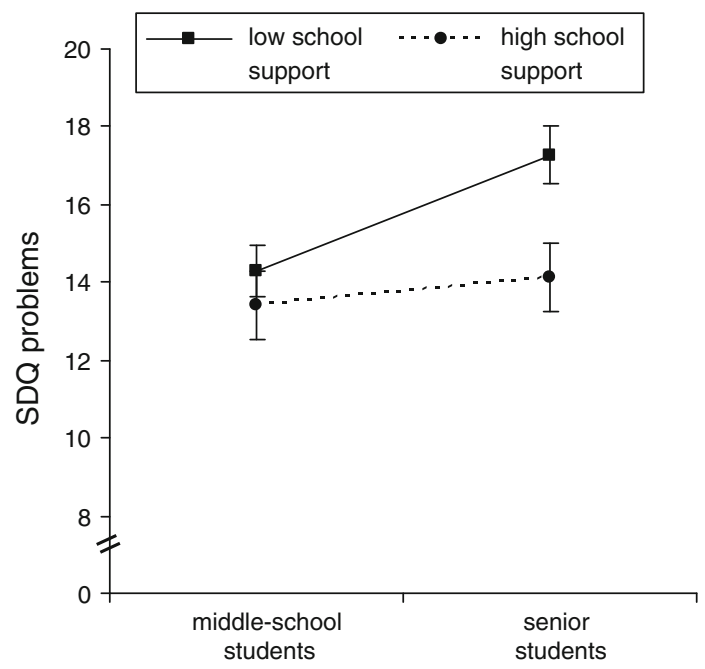

non-victimized adolescents (Figs. 1, 2). A median split was used for subdividing the total sample into students with high and low school support.

Unlike victimized middle school students, in victimized senior high school students mental health problems differ according to school support. The mean total SDQ score in peer-victimized senior high school students with low school support was 17.28 $(\mathrm{SD}=5.26)$, whereas the mean score in peer-victimized senior high school students with high school support was $14.12(\mathrm{SD}=5.64)$. 
Fig. 2 Level of mental health problems (SDQ total score) in non-victimized middle-school students and senior students with high school support $(N=425)$ and low school support $(N=358)$

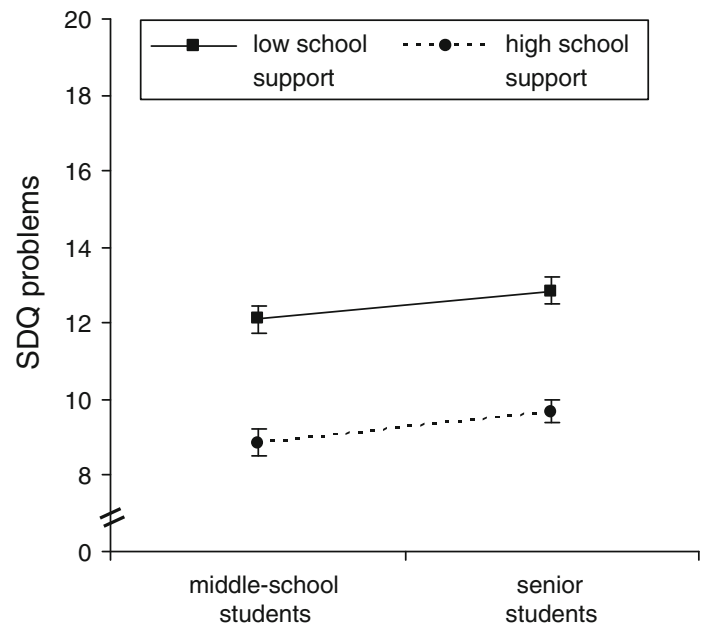

Fig. 3 Level of mental health problems (SDQ total score) in peer-victimized male middleschool students and female middle-school students with high parent support $(N=53)$ and low parent support $(N=48)$

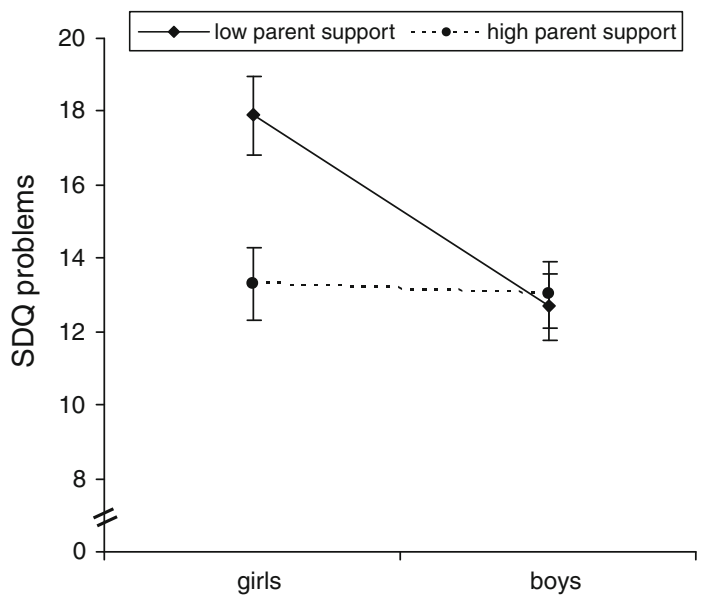

Interactions of Victimization $\times$ Parental Support $\times$ Age and Victimization $\times$ Parental Support $\times$ Gender

Since the interaction of victimization $\times$ parent support $\times$ gender as well as the interaction victimization $\times$ parent support $\times$ age were statistically significant, mental health problems in peer-victimized girls and boys with low and high parental support are represented in Figs. 3, 4, separately for middle school (a) and senior high school students (b). A median split was used for subdividing the total sample into students with high and low parental support.

As illustrated, the mean total SDQ score in 11- to 14-year-old peer-victimized girls with low parental support was $17.89(\mathrm{SD}=4.95)$. Thus, their mean score is more than one standard deviation higher than the mean of Meltzer et al.'s [38] norm sample $(M=10.5$, $\mathrm{SD}=5.1$ ). Unlike girls, 11 - to 14-year-old boys did not differ as a function of parental support. For senior high school students, no interaction between parental support and 
Fig. 4 Level of mental health problems (SDQ total score) in peer-victimized male senior students and female senior students with high parent support $(N=30)$ and low parent support $(N=62)$

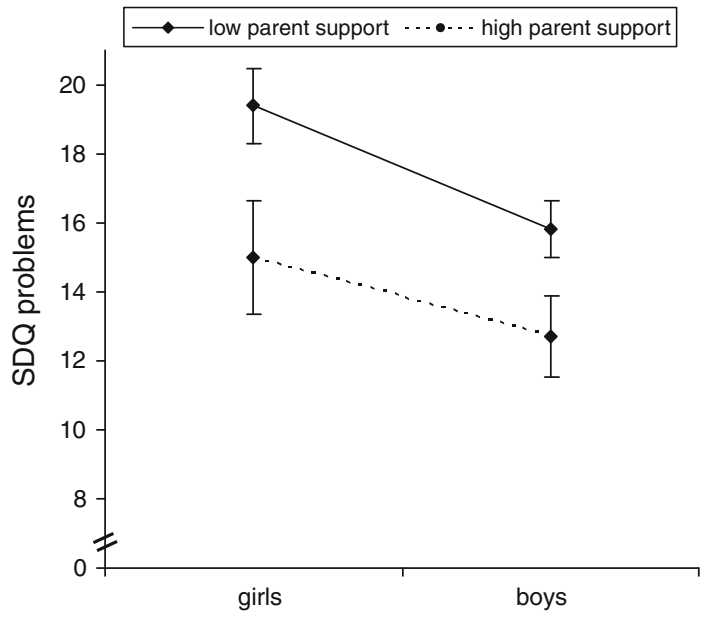

Fig. 5 Level of mental health problems (SDQ total score) in non-victimized male middleschool students and female middle-school students with high parent support $(N=211)$ and low parent support $(N=142)$

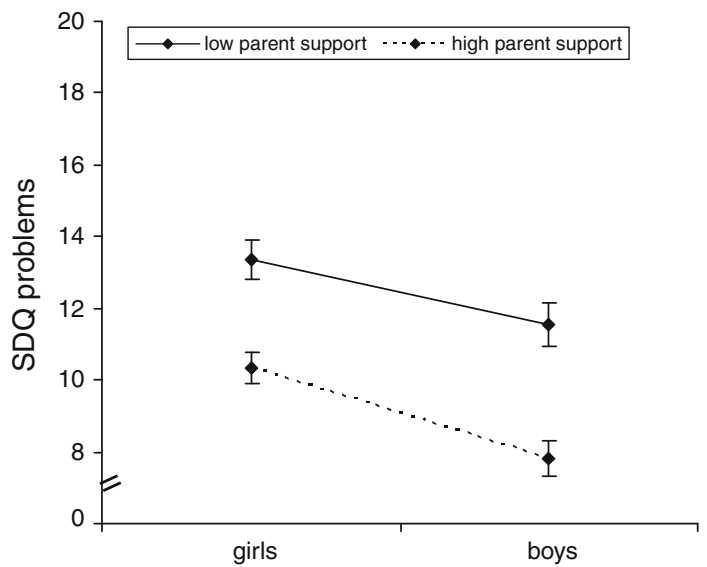

gender was found. Thus, in both girls and boys, low parental support is associated with mental health problems.

Descriptive statistics for the two age groups of non-victimized girls and boys are presented in Figs. 5, 6.

\section{Discussion}

In this study, we assessed the frequency and effects of peer-victimization on adolescents' maladjustment. Specifically, we investigated whether peer-victimized adolescents are protected from developing mental health problems by parental and school support.

Frequency of Peer-Victimization and Its Association with Mental Health Problems

Almost $20 \%$ of adolescents report peer-victimization. The average of $19.8 \%$ in the present sample is in concordance with the mean rate of peer-victimization found in different countries [42]. It was found in the present study that peer-victimization was more common 
Fig. 6 Level of mental health problems (SDQ total score) in non-victimized male senior students and female senior students with high parent support $(N=194)$ and low parent support $(N=236)$

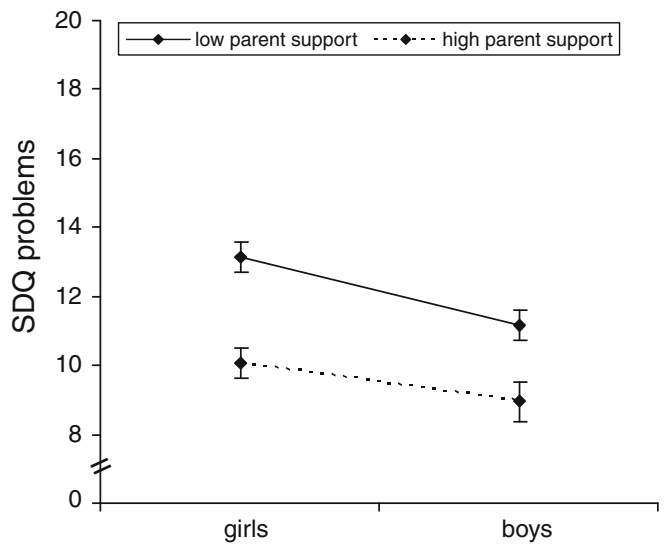

in male than in female students. Furthermore, there is some evidence that the rate of peervictimization in males does not change between middle school and senior high school. Contrary to other studies indicating that peer-victimization steadily declines with increasing age, in our study, a significant decline of peer-victimization was only observed in female students.

In addition, it was shown that in both female and male adolescents, psychosocial risk factors (single-parent family, parental unemployment) are associated with mental health problems, a result that is in line with Ravens-Sieberer et al. [20]. Although accounting only for minor variance, there was a negative relation between school support and psychosocial risk in male students, indicating that, especially in disadvantaged males, school support seems to be lower than it is for males without psychosocial risk factors.

The most important issue of the present study, however, was the question of whether protective factors act as a buffer against peer-victimization.

Parental and School Support as Protective Factors against Maladjustment According to Age and Gender

In order to test the buffering hypothesis, in two regression analyses we analyzed three-way interactions between victimization, support, and gender and age effects. A slightly different pattern of protective factors resulted between gender and age, suggesting that the impacts of peer-victimization may differ between male and female adolescents and also between middle school and senior high school students. Our results showed that parental support is most effective in moderating the effects of peer-victimization for young female students. High levels of parental support (parental support above the median of our study sample) appear to offer protection against maladjustment, especially in female adolescents. In this way, well-functioning families may provide a protective buffer against the risk of peervictimization. Especially in young female students, a family providing security and support to which girls can turn for support after experiencing peer-victimization and where they can talk about their negative experiences may diminish maladjustment. Our results showed, however, that older female students do not benefit from parental support as they might feel too mature to accept their parents' support. On the other hand, our results clearly show that peer-victimized girls appear to be at higher risk for developing mental health problems if parental support is low. 
Concerning school support, the results of the regression analysis revealed a significant buffering victimization $\times$ school support $\times$ age interaction, indicating that in senior high school students, school support might offset the impact of peer-victimization. School support may gain importance for senior high school students, whereas for younger students, other protective factors like family support (especially in girls) are more relevant.

Although the rate of peer-victimization among females declined from middle school to senior high school, those adolescents still targeted by peer-victimization in senior high school seem to have more emotional and behavioral problems. A cumulative effect of peervictimization might be discussed in which the longer victimization lasts, the more dramatic is its effect on adjustment. To further elucidate protective and risk factors in developing mental health problems, longitudinal studies are necessary in addition to cross-sectional studies.

\section{Clinical Relevance of Mental Health Problems: Comparison with Normative Data}

Results of this study clearly support the argument that peer-victimization places adolescents at serious risk for maladjustment. This finding is consistent with previous research $[6,8,12]$. With regard to normative data [38], in the present study the SDQ level of 10- to 14-year-old peer-victimized girls lies more than one standard deviation above the mean of a representative control sample $(N=2135)$, indicating that emotional well-being and behavior are profoundly affected.

In 15- to 18-year-old adolescents, however, we found that female students as well as male students are at high risk for developing mental health problems if parental support is low. Although one might have expected that the moderating effect of parental support attenuates with age, our results contradict this assumption. Parental support seems to be more necessary for 15- to 18-year-old male adolescents than for 11- to 14-year-old adolescents. It can be hypothesized that for male middle school students, other protective factors might be more effective than parental support, e.g., support from good friends [43]. Future research is necessary to address this aspect.

\section{Limitations}

As a cross-sectional design was employed in the present study, a clear direction of effects cannot be inferred. This must be the object of additional longitudinal studies. There are some further limitations of this study that have to be discussed as well. The assessed measures give only a limited scope of information as all data were obtained by adolescent self-report. A more objective result could have been achieved if additional data had been obtained from teacher and parent reports of protective factors. However, it must be assumed that refusal of study participation would have been higher if teacher and parent ratings had been assessed in addition to self-reports. Thus, the strength of this study is its large number of participating students. Furthermore, since the level of mental health problems was related to normed population measures, stronger conclusions and greater generalizability regarding the effects of peer-victimization are possible.

Finally, although the sizes of the interaction effects were not large in magnitude, even small effects may affect public health substantially [43, 44], especially given the high prevalence of adolescents being peer-victimized.

In sum, this study represents progress in elucidating the relation between peer-victimization and mental health problems. Results clearly showed that peer-victimization is 
strongly associated with clinically relevant mental health problems and that protective factors like parental or school support might protect against the negative effect of peervictimization. Increased knowledge about the processes of parental and school support from studies such as this contribute to both the effectiveness of intervention efforts and the promotion of supportive systems that create safer places for adolescents to develop and thrive.

Since the effect of peer-victimization can be offset by parent and school support, educational interventions must be considered. At the level of the classroom unit, social competence training might be helpful, first, to interrupt negative group dynamic processes in the classroom and school environment and second, to train students to better cope with physical and verbal attacks or social manipulation. Since especially vulnerable or young students frequently become targets of peer-victimization [45], integrating social competence training in school settings might be an effective and necessary strategy to prevent or reduce the effects of peer-victimization. Furthermore, our findings support the idea that a positive school climate and teachers supportive of their students are as necessary as parental support, especially in senior high school students, in protecting adolescents against peer-victimization.

\section{Summary}

The objective of this study was to investigate the frequency and impact on mental health problems of peer-victimization in adolescents. The most important aim was to examine whether parental and school support might protect peer-victimized adolescents against mental health problems. Furthermore, whether parental and school support interact with one another in attenuating the effect of victimization and whether adolescents, across the demographic contexts of gender and age, benefit similarly from the protective factors in question were investigated.

The Social and Health Assessment (SAHA) survey was conducted among 986 students aged 11-18 years in order to assess risk and protective factors and mental health problems. For mental health problems, the Strengths and Difficulties Questionnaire (SDQ) was used. The effects of peer-victimization on mental health problems were additionally related to normative SDQ data to obtain information about clinically relevant psychopathology in the investigated study sample.

Results revealed that peer-victimization is associated with clinically relevant mental health problems. In addition, it was shown that parental and school support offset the effects of peer-victimization on maladjustment. Parental support seems to be an effective protective factor against peer-victimization in female middle school students, whereas school support seems to be more important in senior high school students.

Open Access This article is distributed under the terms of the Creative Commons Attribution Noncommercial License which permits any noncommercial use, distribution, and reproduction in any medium, provided the original author(s) and source are credited.

\section{References}

1. Olweus D (1991) Bully/victim problems among school children: basic facts and effects of a school based intervention program. In: Pepler DJ, Rubin KH (eds) The development and treatment of childhood aggression. Lawrence Erlbaum, Hillsdale, pp 411-448 
2. Olweus D (1993) Bullying at school: what we know and what we can do. Blackwell, Oxford

3. Leymann H (1993) Mobbing: Psychoterror am Arbeitsplatz und wie man sich dagegen wehren kann. [Mobbing: Terrorization at work-and how to ward it off]. Rowohlt, Reinbek

4. Olweus D (1992) Bullying among schoolchildren: intervention and prevention. In: Peters RD, McMahon RJ, Quinsley VD (eds) Aggression and violence throughout the lifespan. Sage, Newbury Park, pp 100-125

5. Smith PK, Madsen KC, Moody JC (1999) What causes the age decline in reports of being bullied at school? Toward a developmental analysis of risks of being bullied. Educ Res 41:267-285

6. Gasteiger Klicpera B, Klicpera C (2001) Viktimisierung durch Gleichaltrige als Entwicklungsrisiko [Victimization by peers as a developmental risk factor]. Z Kinder Jugendpsychiatr Psychother 29(2): 99-111

7. Rigby K (1998) The relationship between reported health and involvement in bully/victim problems among male and female secondary school children. J Health Psychol 3:465-476

8. Grills AE, Ollendick TH (2002) Peer-victimization, global self-worth, and anxiety in middle school children. J Clin Child Adolesc Psychol 31(1):59-68

9. Camodeca M, Goossens FA, Meerum Terwogt M, Schuengel C (2002) Bullying and victimization among school-age children: stability and links to proactive and reactive aggression. Soc Dev 11:332345

10. Hanish LD, Guerra NG (2002) A longitudinal analysis of patterns of adjustment following peer victimization. Dev Psychopathol 14:69-8913

11. Troop-Gordon W, Ladd GW (2005) Trajectories of peer victimization and perceptions of the self and schoolmates: precursors to internalizing and externalizing problems. Child Dev 76(5):1072-1091

12. Hawker DS, Boulton MJ (2000) Twenty years' research on peer victimization and psychosocial maladjustment: a meta-analytic review of cross-sectional studies. J Child Psychol Psychiatry 41:441-455

13. Holtmann M, Poustka F, Schmidt MH (2004) Biologische Korrelate der Resilienz im Kindes- und Jugendalter [Biological correlates of resilience in childhood and adolescence]. Kindheit und Entwicklung 13(4):201-211

14. Haden SC, Scarpa A (2008) Community violence victimization and depressed mood: the moderating effects of coping and social support. J Interpers Violence 23:1213-1234

15. Rutter M (1985) Resiliance in the face of adversity: protective factors and resistance to psychiatric disorder. Br J Psychiatry 147:598-611

16. Rutter M (1990) Psychosocial resilience and protective mechanisms. In: Rolf J, Masten A, Cichetti D, Nuechterlein KH, Weintraub S (eds) Risk and protective factors in the development of psychopathology. Cambridge University Press, Cambridge, pp 181-214

17. Spriggs AL, Iannotti RJ, Nansel TR, Haynie DL (2007) Adolescent bullying involvement and perceived family, peer and school relations: commonalities and differences across race/ethnicity. J Adolesc Health 41(3):283-293

18. Garmezy N (1991) Resilience in children's adaption to negative life events and stressed environments. Pediatr Ann 20(9):459-460

19. Wallen J, Rubin RH (1997) The role of the family in mediating the effects of community violence in children. Aggress Violent Behav 2(1):33-41

20. Ravens-Sieberer U, Wille N, Erhart M (2007) Psychische Gesundheit von Kindern und Jugendlichen in Deutschland. Ergebnisse der BELLA-Studie im Kinder- und Jugendgesundheitssrvey (KiGGS). [Mental health of children and adolescents in Germany. Results from the BELLA study within the German Health Interview and Examination Survey for Children and Adolescents (KiGGS)]. Bundesgesundheitsblatt Gesundheitsforschung Gesundheitsschutz 50(5-6): 871-878

21. Bonny AE, Britto MT, Klostermann BK et al (2000) School disconnectedness: identifying adolescents at risk. Pediatrics 106(5):1017-1021

22. Nutbeam D, Smith C, Moore L et al (1993) Warning! Schools can damage your health: alienation from school and its impact on behavior. J Paediatr Child Health 29(Supplement 1):25-30

23. Hill HM, Madhere S (1996) Exposure to community violence and African American children: a multidimensional model of risk and resources. J Community Psychol 24:26-43

24. Luthar SS (1991) Vulnerability and resilience: a study of high-risk adolescents. Child Dev 62:600-616

25. Luthar SS, Cicchetti D, Becker B (2000) The construct of resilience: a critical evaluation and guidelines for future work. Child Dev 71:543-562

26. Seiffge-Krenke I (2005) Aggressionsentwicklung zwischen Normalität und Pathologie. [The development of aggression between normality and psychopathology.] Göttingen: Vandenhoeck \& Ruprecht

27. Paquette JA, Underwood MK (1999) Gender differences in young adolescents' experiences of peervictimization: social and physical aggression. Merrill Palmer Q 45:242-266 
28. Paul JJ, Cillessen AHN (2003) Dynamics of peer-victimization in early adolescence: results from a four-year longitudinal study. J Appl Psychol 19:25-43

29. Prinstein MJ, Boergers J, Vernberg EM (2001) Overt and relational aggression in adolescents: socialpsychological adjustment of aggressors and victims. J Clin Child Psychol 30:479-491

30. Gorman-Smith D, Henry DB, Tolan PH (2004) Exposure to community violence and violence perpetration: the protective effects of family functioning. J Clin Child Adolesc Psychol 33(3):439-449

31. Weissberg RP, Voyce CK, Kasprow WJ, Arthur MW, Shriver TP (1991) The social and health assessment. Zuthors, New haven

32. Schwab-Stone ME, Ayers TS, Kasprow W, Voyce C, Barone C, Shriver T, Weissberg RP (1995) No safe haven: II: the effects of violence exposure on urban youth. J Am Acad Child Adolesc Psychiatry 34:1343-1352

33. Schwab-Stone ME, Chen C, Greenberger E, Silver D, Lichtmann J, Voyce C (1999) No safe haven. II: the effects of violence exposure on urban youth. J Am Acad Child Adolesc Psychiatry 38:359-367

34. Goodman R (1997) The strength and difficulties questionnaire: a research note. J Child Psychol Psychiatry 38:581-586

35. Achenbach TM (1991) Manual for the child behavior checklist/4-18 and 1991 Profile. Department of Psychiatry, University of Vermont, Burlington, VT

36. Goodman R, Scott S (1999) Comparing the strength and difficulties questionnaire and the child behavior checklist: is small beautiful? J Abnorm Child Psychol 27:17-24

37. Bettge S, Ravens-Sieberer U, Wietker A, Hölling H (2002) Methodological comparison between the child behavior checklist and the strengths and difficulties questionnaires. Gesundheitswesen 64(Suppl 1):119-124

38. Meltzer H, Gatward R, Goodman R, Ford F (2000) Mental health of children and adolescents in Great Britain. The Stationery Office, London

39. Mynard H, Joseph S (2000) Development of the multidimensional peer-victimzation scale. Aggress Behav 26:169-178

40. Trumpeter NN, Warson PJ, Leary BJ, Weathington BL (2008) Self-functioning and perceived parenting: relations of parental love inconsistency with narcissism, depression, and self-esteem. J Genet Psychol 169(1):51-71

41. Aiken LS (1991) Multiple regression: testing and interpreting interactions. Sage, Newbury Park

42. Smith PK, Madsen KC, Moody JC (1999) What causes the age decline in reports of being bullied at school? Toward a developmental analysis of risks of being bullied. Educ Res 41:267-285

43. Bollmer JM, Milich R, Harris MJ, Maras MA (2005) A friend in need: the role of friendship quality as aprotective factor in peer victimization and bullying. J Interpers Violence 20(6):701-712

44. Heinrich CC, Schwab-Stone ME, Fanti KA, Jones SM, Ruchkin V (2004) The association of violence exposure with academic achievement and feeling safe at school: is it moderated by parent support? A prospective study. J Appl Dev Psychol 25:327-348

45. Rosnow RL, Rosenthal B (1989) Statistical procedures and the justification of knowledge in the psychological sciences. Am Psychol 44:1276-1284 